\title{
CRÓNICA DE UN EXILIO FORZADO. LA EMIGRACIÓN CLANDESTINA DE JUDEOCONVERSOS ESPAÑOLES COMO RESPUESTA AL INCREMENTO DE LA PRESIÓN INQUISITORIAL A MEDIADOS DEL SIGLO XVII
}

por

\section{ELVIRA PÉREZ FERREIRO}

I.E.S. Francisco Giner de los Ríos. Alcobendas. Madrid

RESUMEN: El aumento de la represión inquisitorial tras la caída del conde-duque de Olivares y la sustitución del Inquisidor General Sotomayor por Arce Reinoso (1643), forzó el ocultamiento y exilio de muchos judeo-conversos que se sintieron en grave peligro. Un conjunto de cartas remitidas por Francisco Fernández Miranda a su hermano Simón, administrador de rentas reales y residente en Madrid, nos acercan a la problemática de estos exiliados forzados y nos sitúan ante las estrategias para ocultar la buída y las repercusiones que, para la vida familiar y social, generaría su decisión. Las dificultades de inserción en los países y comunidades de destino forzaron a parte de estos exiliados a regresar nuevamente a España donde trataron de pasar desapercibidos cambiando nombres y lugares de residencia. Esta movilidad tendría un papel destacado en el mantenimiento de la comunicación entre los que vivían como cristianos en la Península y los que lo bacían como judíos en otros lugares de Europa, reforzando los vínculos y creencias de los primeros.

PALABRAS Clave: Exilio. Éxodo. Judeoconversos. Inquisición.

ABSTRACT: The accentuation of inquisitorial repression after the fall of the Count-Duke of Olivares and the substitution of the General Inquisitor Sotomayor by Arce Reinoso in 1643 forced many Jewish conversos into biding and exile. A series of letters sent by Francisco Fernández Miranda to bis brother Simón, an administrator of royal income who resided in Madrid, describes the problems of these forced exiles, the strategies used to bide their escape routes, and the repercussions for their social and family life. The difficulties that these exiles had in settling in their new countries or communities forced some to return to Spain where they tried to pass unnoticed by changing their names and places of residence. This mobility had an important role in the maintenance of communication between Jewish people who were living as

Hispania, LXIV/2, núm. 217 (2004) 543-570 
Christians in Spain and those living as Jews in other places of Europe, reinforcing the ties and beliefs of the former.

KEY WORDS: Exile. Exodus. Conversos. Inquisition. Spain. Seventeenth Century.

Era un tórrido día de agosto del año 1654. Simón Fernández Miranda, un conocido hombre de negocios madrileño, administrador de rentas reales, salió de su casa en la calle Carretas de Madrid para acudir a la estafeta y recoger una carta remitida desde Burgos por un tal D. Francisco de Guzmán. Meses más tarde recogería otras cartas del mismo remitente fechadas en Vitoria y Pamplona $^{1}$. La correspondencia entre ambos personajes se prolongó durante todo el año 1655 y los primeros meses de $1656^{2}$ y hoy, cuando han transcurrido más de 350 años, estas cartas se nos presentan como una crónica precisa del camino y dificultades a que se vieron abocados por aquellos años muchos españoles para lograr sobrevivir en un ambiente de fuerte hostigamiento hacia los descendientes de los judeoconversos españoles.

Cuando Simón recogió la primera de estas cartas acababa de regresar a Madrid después de finalizado un proceso en Cuenca que afectó a casi toda su familia. Ordenaba por entonces sus negocios y ponía al día las cuentas para poder pagar las multas impuestas por la Inquisición como parte de las sentencias familiares. Había sido un año antes, en agosto de 1653, cuando la familia, como tantas otras familias madrileñas en aquel momento, fue detenida y conducida a las cárceles secretas de la inquisición conquense donde se desarrollaron los correspondientes procesos tras la acusación formal del fiscal por sospechas de prácticas judaicas ${ }^{3}$. En junio de 1654 se le leyó su sentencia ante los miem-

* Siglas: A.H.N.: Archivo Histórico Nacional; A.D.C.: Archivo diocesano de Cuenca; Leg.: legajo; Lib.: libro; Inq.: Sección Inquisición; BRAH: Boletín de la Real Academia de la Historia; CoDOIN: Colección de documentos inéditos, publicados en 110 vols. por la R.A.H.

1 Es posible que los lugares de procedencia de las cartas aparezcan alterados como medida de seguridad.

2 Estas cartas, que se han conservado entre la abundantísima documentación secuestrada por la Inquisición a esta familia, nos han permitido acercarnos a la experiencia singular de un grupo de españoles que, en estos años centrales de la quinta década del XVII, se sintieron tan amenazados en su país por ser lo que eran que tuvieron que desarrollar estrategias singulares, en ocasiones espectaculares, para salir de España sin ser detectados por la Inquisición. Es un retazo de la historia de la emigración ideológica y política de nuestro país. Las cartas se encuentran en A.H.N. Inq. Leg. 4275/2.

3 Las detenciones de sospechosos de herejía judaica en el Madrid de los primeros años 50 del XVII fueron tan numerosas que la prisión inquisitorial toledana se vio totalmente desbordada. Muchos de los detenidos en Madrid tuvieron que ser conducidos a las prisiones de Cuenca y Valladolid. Sobre el incremento de la represión de estos años podemos consultar ente otros los trabajos de CARo BAROja, J.: Los judíos en la España Moderna y Contemporánea, vol.II, Madrid, 1978, pp. 81-90; Domínguez ORTIZ, A.: Los judeoconversos en España y América. Madrid, 1978, pp. 73-75 y Política y Hacienda de Felipe IV (1621-1665). Madrid, 1960; p. 120; PÉREZ VILlanUeVA, J.: «Felipe IV y su

Hispania, LXIV/2, núm. 217 (2004) 543-570 
bros del tribunal que le reprendieron, limitando su condena a 4 años de destierro a 10 leguas de Cuenca y Madrid. Pese a no haber condena formal ni multa, los gastos generados en la prisión, a los que tenía que hacer frente, ascendieron a 1.592 reales y por las multas de su mujer Teodora, su suegra Isabel Núñez y su hija Isabel de Miranda, también presas y procesadas en el mismo periodo, habría de pagar 12.100 reales $^{4}$.

La detención de la familia Miranda había supuesto un durísimo golpe para sus familiares y amigos íntimos que se sintieron amenazados y dominados por el temor de correr su misma suerte. A la angustia de los primeros momentos siguieron la reflexión y el planeamiento de estrategias de movilización y ocultamiento. La prisión despertaba siempre mecanismos soterrados de inseguridad y temor con los que hubieron de convivir muchos de los que no se identificaban con el sentir y vivencias mayoritarias. Bennassar nos ha situado magistralmente ante la desesperación y el miedo que despertaban los procesos inquisitoriales. En los largos y reiterados interrogatorios a que el tribunal sometía a los procesados, y durante las sesiones de tormento, muchos rompían el silencio denunciando a otros, familiares o amigos, de compartir con ellos las creencias y vivencias por las que se les juzgaba. Cada individuo que delataba a otros, cada voluntad rota, se convertía habitualmente en el punto de partida de nuevas detenciones. Así que los que sabían o sospechaban que habían sido denunciados - testificados - reaccionaban cambiando de nombres, domicilio o liquidando sus bienes para emprender el camino del exilio. Eran recursos para intentar ponerse a salvo de la prisión, el tormento, la pérdida de bienes y, siempre, de la tan temida deshonra social ${ }^{6}$.

política», en J. Pérez Villanueva (Dr.), Historia de la Inquisición en España y América, vol. I. Madrid, 1984, pp. 1006-1008; KAMEN, H.: La Inquisición española. Barcelona, 1988, p. 295 o SCHREIBER, M.: "Cristianos nuevos de Madrid ante la Inquisición de Cuenca (1650-1670)», en J. Pérez Villanueva (Dr.), Historia de la Inquisición en España y América, vol. III. Madrid, 2000, pp. 544 y 550-555.

4 Sobre la evolución de este grupo familiar he escrito en «Desde Ciudad Rodrigo a la Corte de su Majestad. Triunfo y ocaso de una familia mirobrigense de origen converso a través de nueve generaciones» en Actas Congreso de Historia de la diócesis de Ciudad Rodrigo, vol. II. C. Rodrigo, 2002, pp. 681-708. El proceso de Simón F. Miranda se encuentra en el A.D.C. Inq. Leg. 489/6550. En la correspondencia entre el tribunal y el Consejo de la Suprema encontramos la confirmación detallada del alcance económico de las penas impuestas en esta ocasión a la familia Miranda. Carta de 29 de Julio de 1654, en A.D.C. Inq. Lib. 243, fol. 281.

5 Estrategia tan común y conocida que el propio Consejo de la Suprema se hacía eco de ella, alertando a los tribunales inquisitoriales sobre sus consecuencias. En una Carta Acordada remitida en 1574 leemos: «en el Consejo se a tenido relación que muchos confesos descendientes de condenados y reçonciliados por el Sancto Officio de la Inquisición, mudan los nombres y apellidos que tenían sus antecesores y toman otros diferentes, a fin y efecto de que no sean conoçidos por descendientes de los tales condenados y reconciliados y que por los libros del Sancto Officio no se puedan averiguar sus genealogías...» A.H.N. Inq. Lib. 326, fol. 228.

6 BENNASSAR, B. «La Inquisición o la pedagogía del miedo», en BENNASSAR, B. (Dr.): La Inquisición española: poder político y control social. Barcelona, 1984, pp. 94-125. 
En este caso concreto, y muy poco después de ser encarcelados los Miranda, la Inquisición firmó la orden de prisión para Baltasar Fernández de Paz, primo de la mujer de Simón y colaborador suyo en el arrendamiento de millones en Valladolid. Baltasar fue buscado infructuosamente en Madrid, Valladolid y Medina del Campo sin que pudieran dar con él7. Había, en efecto, logrado reaccionar a tiempo y ponerse a salvo. Fue, empero, un respiro pasajero ya que, cuando creyó calmada la situación, regresó a Castilla buscando proseguir su actividad mercantil en un nuevo escenario territorial y así lo hizo hasta que el 17 de marzo de 1659 fue detenido en Madrid por Pedro Sánchez Prieto, familiar del Santo Oficio, y trasladado a la prisión inquisitorial de Cuenca. A la vera del Huécar se desarrolló su proceso basado en las denuncias de ocho personas que habían testificado contra él haciéndolo sospechoso de prácticas judaicas. Durante este proceso Baltasar reconoció haber viajado a través de San Sebastián hasta Bayona, asegurando que había regresado ya en 1656. Tras algo más de 3 años de cárcel, en Agosto de 1662, la sentencia le condenó a abjurar de vehementi, pagar una multa de 500 ducados al Santo Oficio y exiliarse durante 6 años a 10 leguas de Madrid y Cuenca ${ }^{8}$.

También desde Andalucía, donde residía buena parte de la familia, se intentaba reaccionar antes de que fuese demasiado tarde. No sabemos por qué fue Francisco Fernández de Miranda, hermano menor de Simón, el que se sintió más amenazado, aunque cabe suponer que tuvo indicios de que la Inquisición tenía testificaciones contra él. Lo cierto es que el que fuera durante años propietario de una fábrica de aguardiente, además de escribano, en Antequera (Málaga), organizó cuidadosamente su viaje clandestino a Francia y cuando Simón regresó a Madrid, y apoyándose en él, inició uno de los caminos habituales hacia el exilio, aquel que pasaba por Alcobendas hacia Burgos, continuaba hasta Vitoria o Pamplona y seguía hasta San Sebastián para acabar cruzando la frontera, generalmen-

7 Baltasar se quedó al frente de la administración de las sisas de millones de Valladolid, concedidas a Simón en 1646, cuando éste regresó con su familia a Madrid hacia 1649. Desde el tribunal de Valladolid escribían el 7 de Octubre de 1653 al Consejo indicando que no habían podido encontrar a Baltasar y que, según las informaciones que tenían, se habría ido a Francia al conocer la prisión de los Miranda. Los inquisidores sabían que había escrito una carta desde San Sebastián. Según el mismo Baltasar confirma en su proceso años más tarde su madre María López, hermana de Isabel Núñez, la suegra de Simón, residía en Flandes. Otras fuentes la sitúan en Peñaorada. Véase A. H. N. Inq. Leg. 170/1. Proceso 4, fol. 23.

8 A.D.C. Inq. Leg. 516/6717. Entre la correspondencia del leg. 4275/2 del A.H.N. se encuentra la carta a la que hemos hecho referencia, fechada en San Sebastián a 8 de Septiembre de 1655 y dirigida a Simón Fernández Miranda, dándole noticias de su hermano Francisco que todavía esperaba la llegada de su mujer e hijos en las proximidades de la frontera: «el señor Velasco está bueno y escribe ... y sintió ynfinito el que ubiese detención de ynviarle las mercadurías por necesitar de valerse de ellas y que, respeto de que puede haber riesgo en su detençión, estimará el que se consiga su remisión en breve porque en todas partes haxe gasto...». Se refiere al viaje de la familia de Francisco Fernández Miranda, como veremos.

Hispania, LXIV/2, núm. 217 (2004) 543-570 
te con la ayuda de personas expertas que facilitaban la huída9. En Antequera quedaron, por entonces, su mujer Clara Delgado y sus 2 hijos pequeños: Jorge Mateo de 3 ó 4 años y una niña de poco más de un año. El viaje de toda una familia era demasiado significativo para que pudiese pasar desapercibido ${ }^{10}$.

Aquel D. Francisco de Guzmán, o D. Francisco Antonio Velasco de otras cartas, era en realidad Francisco Fernández Miranda, hermano de Simón ${ }^{11}$.

El sentimiento de peligro decidió a Francisco a dejar su Andalucía natal donde siempre había vivido y arriesgarse a cruzar la frontera buscando un espacio de libertad. Las peripecias que aquel viaje que proyectaba implicaba no eran teóricamente desconocidas para Francisco. Por aquellos días estos temas eran parte de muchas conversaciones privadas entre los conversos que habían visto cómo, tras la caída del valido del rey, el conde-duque de Olivares, y la sustitución de Sotomayor por Arce Reinoso al frente de la Inquisición (1643), se había ido incrementando continuamente la represión hacia ellos ${ }^{12}$. Muchos como él optaron en aquellos días por el exilio para vivir al Norte de los Pirineos en un marco de relativa libertad su existencia como cristianos o bien regresar al judaísmo que con fidelidad y celo habían heredado y les habían transmitido sus mayores ${ }^{13}$.

9 Algunas de estas rutas e itinerarios clandestinos fueron descritas por los guías de la huída cuando caían en manos de los inquisidores. Lo hizo así Rafael Gómez Herrera en A.H.N. Inq. Leg. 170/1. Proceso 5, fol. 39 o Francisco Núñez Redondo, citado por CiraC Estopañán, S.: Registro de los documentos del Santo Oficio de Cuenca y Sigüenza. Cuenca, 1965, pp. 55-56.

10 Francisco que tenía unos 52 años en este momento y al que al inicio de los años 60 un denunciante describía como «un hombre alto y espalduro, de ojos reventones y boca grande», había estado casado anteriormente 2 veces. La primera con Catalina de Ayala, de cuyo matrimonio vivía un hijo, Pedro de Miranda, dedicado a la administración de rentas reales en Antequera y que en los años 60 se trasladó a Madrid. De su segundo matrimonio con Felipa de Tábara tenía dos hijos: Antonio de Miranda e Isabel Ana de Miranda que vivieron y trabajaron en Madrid al amparo de su tío Simón. Felipa era originaria de Lisboa y, tanto ella como su hermana Leonor, habían sido procesadas por la Inquisición de Granada en 1647. Felipa ingresó en la cárcel granadina enferma y sólo 4 meses después de haber dado a luz. Su causa fue suspendida después de 8 meses de prisión. A.H.N. Inq. Leg.2632. (Debo esta última referencia a Flora García Ivars, estudiosa del tribunal granadino). Clara, su tercera esposa, era natural de Estepa. Se casó con Francisco tras trasladarse a Antequera y enviudar éste. La documentación la describe como «pequeña, de boca grande, cabello negro azabache, blanca y bien carnuda y parecida, con un lunar con pelos negros en el cuello». A.H.N. Inq. Leg.184/14, fol.15.

11 El hecho de que todas estas cartas se hayan conservado en el mismo legajo (Leg. 4275/2, ya citado) nos ha facilitado el trabajo de identificación. No hay duda, la letra, giros y expresiones corresponden a la misma persona. De igual modo ocurre con las cartas de Clara Delgado y las notas que aparecen al final de las cartas de Francisco Guzmán a partir de 1656 firmadas por M. Ángeles o, en otras ocasiones por Dọna Magdalena de la Torre. Siempre son Clara Delgado y Francisco Fernández Miranda los que escriben.

$12 \mathrm{El}$ profesor Beinart ha alertado sobre la existencia de reuniones en Madrid y otros lugares donde se planificaban cuidadosamente estos viajes clandestinos. BeINART, H.: El legado de Sefarad, vol. II. Jerusalem, 1993, p. 55.

13 Julio Caro Baroja ha subrayado que muchos de los que salían lo hacían para ser judíos públicamente. Caro Baroja, J.: 1978, II, pp. 84-85. Pero es incuestionable que otros muchos de los exiliados bajo el temor a la pérdida de libertad y a la acción inquisitorial, se sentían y vivían como [cris- 


\section{BRUSCOS VIRAJES EN LA POLÍTICA OFICIAL HACIA LOS JUDEOCONVERSOS.}

Con la llegada de la decimoséptima centuria muchos de los judeoconversos españoles gozaron de un respiro que les permitió liberar parte del temor a la pérdida de libertad y a la marginación social que era habitual para muchos de ellos. La subida al trono de Felipe III, en un contexto socio-cultural más tolerante con la diversidad, tanto en España como en el resto de Europa, abría caminos de esperanza a una situación más propicia para ellos $^{14}$.

Desde el inicio de la centuria la eliminación de trabas a la emigración de los conversos hispanos (1601) fue respondiendo a algunas de sus aspiraciones a la vez que propició una fuerte oleada de emigrantes que desde Portugal acudían a Castilla, pero también a Francia, Holanda, Italia y otros destinos ${ }^{15}$. El perdón general que el papa concediera a los condenados por razón de sus creencias, y que supuso la liberación de la cárcel de muchos conversos (1604), marcó un nuevo hito en aquel camino de reconciliación y relativa tolerancia que parecía abrirse paso, y que las penurias hacendísticas propiciaban, ya que las concesiones iban precedidas de generosas indemnizaciones a las arcas de la hacienda pública.

$\mathrm{Y}$, aunque estas concesiones reales se suspendieron en 1610 por la alarma que estaba creando esta masiva emigración de portugueses fuera de Portugal y aún de la Península, muchas voces y plumas se esforzaban en reclamar posibilidades reales de integración para aquel sector de la sociedad con ancestros judaicos. A la altura de 1619, el arbitrista Martín González de Cellorigo, uno de los representantes de esta corriente, demandaba de la Corona medidas que frenasen el hostigamiento desplegado contra los judeoconversos por el bien de las finanzas y el comercio ${ }^{16}$. Con todo, podemos considerar las primeras décadas de este siglo como un periodo propicio durante el cual la mayoría de los judeoconversos pudieron vivir en Castilla tranquilos, progresar y, algunos incluso enriquecerse con rapidez, aprovechando el escaso desarrollo empresarial español. Algunos de entre ellos, importantes banqueros portugueses y hombres de negocios lisboetas, se dedicaron con eficacia al comercio y arrendamiento de rentas reales, a la vez que iban sustituyendo a los prestamistas y negociantes genoveses o flamencos que gozaban ya de muy escasa popularidad; otros muchos eran negociantes modestos procedentes con frecuencia del N.E. de Portugal. La situación real de estos años favoreció tanto a los conversos autóctonos como a

tianos. Su origen, empero, les mantuvo ante muchos de sus conciudadanos y ante los] servidores de la Inquisición siempre bajo la sospecha de prácticas heréticas.

14 Sobre el contexto internacional puede consultarse ISRAEL, Y. I.: La judería europea en la época del mercantilismo (1550-1750). Madrid, 1992, pp. 55ss.

15. El Inquisidor Murcia de la Llana denunciaba la llegada masiva de portugueses a Madrid en este periodo. Caro Baroja, J. 1978, II, 48.

16 RÉVAH, I. S.: «Le plaidoyer en faveur des "Nouveaux chrétiens" portugais du licencié Martín González de Cellorigo", en Revue des Etudes juives, vol. I, 121, 1962, pp. 279ss e IsRAEL, Y. I.: 1992, p. 79. 
los portugueses que continuamente se trasladaban a tierras castellanas. Además la Inquisición seguía, por estos años, más preocupada por los problemas derivados de la reforma católica que de la supuesta herejía de los descendientes de los hebreos.

Es fácil comprender que la nueva orientación de las máximas autoridades civiles y religiosas hacia la minoría convertida del mosaísmo despertara reacciones contrapuestas. De esperanza unas, de sospecha y temor las otras ${ }^{17}$.

Coinciden estos años bonancibles con la percepción de que algunos de los comerciantes conversos estaban enriqueciéndose ilegalmente, a través del contrabando. En el contexto de la Guerra de los Treinta años (1618-1648), los comerciantes sefardíes residentes en Holanda se encontraban en mejores condiciones de burlar las severas restricciones impuestas por España al comercio que el resto de sus colegas holandeses debido a sus intensas relaciones con parientes, amigos y socios en la Península Ibérica:

«desde 1621, con los puertos vetados a los barcos holandeses, se desplegó un floreciente contrabando entre Amsterdam y Madrid, especialmente de telas que se intercambiaban por plata y lana; las mercancías eran transportadas por el interior de España hasta Bayona, cruzando Navarra y los pasos de los Pirineos, y viceversa»18

La polémica que estalló en los años 20 continuó durante décadas. Las autoridades estaban seguras de que numerosos conversos, al comerciar con agentes extranjeros, enviaban plata a Holanda e introducían desde allí clandestinamente moneda falsa agravando el caos monetario español de aquellos años. Y no era sólo moneda falsa lo que entraba clandestinamente en España. Desde el N.

17 El profesor Cantera Burgos publicó en 1966 tres memoriales que reflejan estas reacciones. En el primero, el obispo de Plasencia, D. Pedro González de Acevedo, habla de los ocultos y malignos planes que los judíos portugueses tienen respecto a los cristianos e insiste en la necesidad de mantener con todo rigor los Estatutos de Limpieza que les cerraban el paso a numerosos puestos y cargos relegándoles a un segundo plano social. El segundo escrito, atribuido al obispo de Braganza y dirigido al confesor del monarca fr. Gaspar de Córdoba, expresaba con energía su convicción de que entre los conversos no hay ninguna conversión verdadera insistiendo en el daño que ocasionaría un perdón general. Años más tarde, el mismo Cantera publicó otro memorial coetáneo que reflejaba una actitud bien diferente. El autor anónimo pedía al rey la limitación de las investigaciones sobre el origen de sus súbditos a la cuarta generación argumentando que el desmedido afán de limpieza acaba poniendo en duda a la sociedad entera, incluyendo a la nobleza, actitud que coincide básicamente con la expresada por diversos escritos arbitristas y que continúa un debate abierto desde las décadas finales del XVI. CANTERA BURGOS, F.: «El problema de los criptojudíos al escalar el trono Felipe III» en Homenaje al Prof. Alarcos, vol. II, 1966 y « Memorial anónimo dirigido a Felipe III en pro de los conversos originarios del judaísmo», BRAH, CLXVII, 2, 1970, pp. 15-34. Son exponente de los muchos memoriales, tratados o cartas, de una u otra tendencia, escritos por estos años. Algunos de ellos han sido estudiados por Domínguez OrTIZ, A.: La clase social de los conversos en Castilla en la Edad Moderna. Madrid, 1955, pp. 86-101. Véase asimismo CARO BAROJA, J.: 1978, II, p. 46.

18 IsRael, Y. I.: 1992, p. 134. 
de Europa llegaban a Castilla partidas de cereales, textiles y madera, siendo los conversos portugueses los que se encargaban de remitirles a cambio lanas, frutas y aceite. Esto era posible gracias a que «los marranos portugueses disponían de una amplia red de contactos comerciales con la región atlántica, con relaciones desde Sevilla a Hamburgo» ${ }^{19}$. En la documentación inquisitorial encontramos frecuentes alusiones a estos hechos.

El año 1621 supuso para el joven príncipe heredero el inicio de sus responsabilidades en el gobierno. La subida al trono de Felipe IV conllevó una nueva mejora en la situación de los conversos hispanos. El valido del nuevo rey, D. Gaspar de Guzmán, conde de Olivares, tenía grandes planes para aquella España todavía dueña de un gran Imperio. Custodiar el patrimonio de los Habsburgo se convirtió en uno de los ejes de su política. Eso exigía mantener un numeroso ejército en Italia, Alemania, los Países Bajos y parte de América y ello suponía una gran carga económica para su rey. Los conversos habían mostrado ya su experiencia y eficacia en los asuntos económico-financieros y en el abastecimiento de las tropas en el anterior reinado. Olivares no sólo no va a prescindir de ellos sino que les abrirá la puerta de Castilla, manteniendo un cierto control sobre la Inquisición. Muchos portugueses entraron en Castilla en estos años. Un éxodo sin precedentes, subraya Yerushalmi ${ }^{20}$. Madrid se convirtió pronto en uno de los destinos preferidos: «Madrid es gran refugio de judíos de este reyno, por razón del tráfago de la tierra» ${ }^{21}$. Sevilla le seguía en importancia por similares razones. Un atento observador de la situación escribía desde Lisboa al Consejo de Hacienda por aquellos días: «en esta ciudad está acabado el comercio, y todos los hombres de negocio que tenían substancia se pasaron a esa Corte y a Sevilla» ${ }^{22}$.

Entre ellos llegaron importantes financieros dispuestos a hacerse cargo de los asientos en sustitución de algunos de los genoveses, a los que la crisis económica y la bancarrota de 1627 habían llevado a la quiebra. Los genoveses tuvieron que aceptar la competencia conversa y ver cómo se rompía el monopolio que habían ostentado. Pagos y suministros al ejército, arrendamiento de rentas reales, percepción de alcabalas, rentas eclesiásticas... muy pronto los conversos se hicieron cargo de buena parte de la gestión de recaudación y tributación del Estado, pese a la prevención que el Consejo de Hacienda había mostrado desde el inicio del reinado, debido a «la mala opinión que los de esta nación que tratan de arrendamientos y mercaderías tienen...». Pero la monar-

19 BROENS, N.: Monarquía y capital mercantil: Felipe IV y las redes comerciales portuguesas (16271635). Madrid, 1989, pp. 28-29. LÓPEZ BELINCHÓN, B. ha estudiado ampliamente estas situaciones en su excelente trabajo: Honra, libertad y Hacienda (Hombres de negocios y judíos sefardíes). Alcalá de Henares, 2001, pp. 295-298.

20 YeRUShALMI, Y. H.: De la Corte española al gueto italiano. Madrid, 1989, p. 58.

21 Acosta, Vicente de, Discurso contra los judíos..., traducido por fr. Diego Gavilán Vela. Madrid, 1680 p. 156, véase CARO BAROJA, J.: 1978, II, p. 59.

22 Véase Domínguez OrTiz, A.: 1960, p. 133.

Hispania, LXIV/2, núm. 217 (2004) 543-570 
quía les necesitaba y la situación abrió camino a nuevas concesiones. Un nuevo Edicto de Gracia para los que confesasen sus culpas en el plazo de 3 meses (1627) y la anulación de la prohibición de matrimonios mixtos (1628) prepararon el camino al decreto que permitía un nuevo y anhelado permiso de libertad de movimientos, tanto de personas como de capitales, dentro y fuera de la $\mathrm{Pe}-$ nínsula (1629). A cambio, nuevamente las arcas del reino recibían el auxilio de un generoso donativo de 250.000 cruzados.

Sólo unos años más tarde, el mismo Consejo sugería aceptar el ofrecimiento de un grupo de banqueros portugueses de proveer 400.000 escudos en Flandes porque, aunque consideraban excesívas sus exigencias, creían que:

«la introducción de estos hombres en hacer asientos con V.M. y poner casa de negocios en esta Corte es muy conveniente, por la competencia que podrán hacer a los ginoveses y las comodidades que con esto se podrán sacar» ${ }^{23}$.

Pese a estas medidas de tolerancia, muchos descendientes de judeoconversos, incluso algunas de las más sobresalientes familias de financieros, como las de Manuel Fernández Pinto, Montesinos, Núñez de Saravia, Pessarinho, etc., fueron condenados o, al menos, tuvieron conflictos con la Inquisición. Algunos fueron encarcelados antes de la caída de Olivares, la mayoría después. La emigración clandestina continuó teniendo tal peso que las autoridades buscaron medidas que frenaran aquella sangría de personas que dañaba las perspectivas de prosperidad para el reino a través de mayores controles en las fronteras o de disposiciones que amenazaban con el embargo de bienes para los exiliados detectados ${ }^{24}$.

El rechazo de parte de la sociedad a este incremento de la presencia de conversos y a su papel en las finanzas y la corte se puso pronto de manifiesto y se volvió contra el conde-duque, que vio crecer su impopularidad tan deprisa como aumentaba el número de pasquines y libelos contra él y el judaísmo de los conversos $^{25}$. En el propio Consejo de Castilla se veía la libertad de movimientos y la llegada masiva de conversos como causa de muchos de los males del momento ${ }^{26}$.

En Madrid se atribuía al valido la intención de traer judíos a España, rumor que reaparece en numerosos momentos de disminución de la presión inquisitorial. Muchos de los coetáneos de Olivares se hicieron eco de ello:

23 Domínguez OrTiZ, A.: 1960, p. 130

24 Caro Baroja, J.: 1978, II, p. 48.

25 Los escritos anónimos frente al supuesto filohebraísmo de Olivares fueron tan numerosos que muchos autores se hicieron eco de ello. Véase Pulido Serrano, I.: "Calderón y Olivares: dependencia y antisemitismo en el barroco", en Manuscrits, 10, 1992, pp. 183-213. En un trabajo más reciente, I. Pulido rechaza el supuesto filojudaísmo de Olivares. Considera al valido representante de una postura alejada de prejuicios religiosos y culturales que buscaba la integración de los descendientes de los conversos en beneficio de la monarquía. Pulido Serrano, I.: Injurias a Cristo. Religión, política y antijudaísmo en el siglo XVII. Alcalá de Henares, 2002, pp. 37-38.

26 Véase QUEVEDO, Francisco de: Execración contra los judíos. F. Cabo y S. Fernández (Eds.). Barcelona, 1996, XX. 
«He sabido por cosa cierta, escribía el cronista José Pellicer, que se trata de restituir y traer los judíos que están en las sinagogas de Holanda y otras partes; para lo cual se han propuesto en un papel veintiocho medios. Opónese a ellos constantemente la Sta. Inquisición. Avisaré de lo que resultare»27.

Matías de Novoa, ayudante de cámara de Felipe IV, reiteraba el mismo rumor:

«He oído decir que los judíos de Orán, y los que habitan la tierra adentro de África tienen aquí sus pretendientes para que los admitan a los contornos de $\mathrm{Ma}$ drid, y les den tierra y suelo en que vivan con libertad y en su ley, y a todos los demás que quisieren habitar con ellos, y se empadronarían y darían muchos millones por la permisión»28.

En 1634, uno de los anónimos correspondientes del jesuita padre Pereira, le comunicaba:

"Valido anda que entran los judíos en España; lo cierto es que entran y salen a hablar con el rey y darle memoriales y hoy vi uno con una toca blanca a la puerta del cuarto del rey» 29 .

27 Pellicer y Tovar, J.: Avisos de 12 de Marzo de 1641. Avisos históricos. Valladares, A. (Ed.), Semanario erudito, vol. 32, p. 16.

28 NovoA, Matías de, Historia de Felipe IV, rey de España, en CodoIN, vol.77. Madrid, 1881, p. 380, véase Domínguez OrTiZ, A.: 1978, p. 68. Numerosos autores apoyan la existencia de estos proyectos, algunos de ellos discutidos en el Consejo de Estado. Véase, por ejemplo, IsRaEL, Y. I.: 1992, p. 139. I. Pulido ha llegado a la conclusión de que se trata de un mito sin apoyo documental que se ha hecho creíble gracias a su reiteración y la confusa utilización de los términos judío y converso. El temor a la llegada de judíos exiliados acentuaría el antiolivarismo, por lo que sería usado por los enemigos del valido para desprestigiarle. PULIDO SERRANO, I.: 2002, pp. 38-49.

29 Seguramente en referencia a Jacob Cansino, un judío de Orán que residió varios años en Madrid como traductor del rey. Barrionuevo se refiere a él en sus Avisos de fecha 29 de abril de 1656: «un judío de Orán, llamado Cansino, viene a Madrid en nombre de los demás, y se dice presta al Rey 800.000 ducados de plata con sus intereses...». BARrIOnUevo, D. Jerónimo de, Avisos. A. Paz y Meliá (Ed.)., vol.I. Madrid, 1968, p. 272. Encontramos referencias a su estancia en Madrid en Domínguez ORTIZ, A.: 1978, p. 68 y en "Judíos de nación y profesión", en FERNÁNDEZ ALBADALEJO y otros (Coords), Política, religión e inquisición en la España moderna. Madrid, 1996, pp. 242-244; Caro Baroja, J.: 1978, I, p. 301 y II, p. 90; Jerushalmi, Y. H.: 1989, p. 96; BeinarT, H. 1993, II, p. 63 e IsRAEL, Y. I.: 1992, p. 139. Hay evidencias de que en situaciones excepcionales algunos judíos recibieron permisos temporales para residir en España por razones comerciales o de interés de la monarquía: informadores, asesores, traductores de árabe..., otros viajaron clandestinamente a España por razones familiares o de negocios. Mercedes García Arenal recientemente ha evidenciado la sorprendente presencia de un grupo de informadores y comerciantes judíos en Madrid y otros lugares del reino. Véase GARCía ARENAL, M. y WIEGERS, G., Entre el Islam y Occidente: vida de Samuel Pallache, judío de Fez. Madrid, 1999, pp. 6,16, 17, 20, 23, 27...

Hispania, LXIV/2, núm. 217 (2004) 543-570 
El año 1640 da paso a un período de fuertes convulsiones para España. Al levantamiento de Cataluña y la sublevación portuguesa se sumaron la derrota de Dumas y la pérdida de Arras, en el exterior. La crítica situación creada acaba con la popularidad del valido que tiene que dejar su cargo. Muy pronto los más negros presagios rodearon a los judeo-conversos castellanos. La insurrección portuguesa despertó un fuerte rechazo popular hacia los portugueses y el mismo monarca, tolerante en otra época, escribía al Consejo de Hacienda sobre los medios de acabar con el poder económico de los conversos. La Inquisición recordaba una vez más con contundencia que había sido creada para luchar contra la herejía conversa e iniciaba una larga carrera persecutoria contra esta minoría de significativo papel social.

Sotomayor, obispo de Málaga y confesor del monarca, que había comprendido el punto de vista del Conde de Olivares y le ayudó en sus planes, cae poco después de ser sustituido el valido de su cargo. Su sucesor, Arce Reinoso (164365), abrirá uno de los períodos más duros de persecución sistemática de la Inquisición hacia esta minoría.

Los conversos que pueden huyen antes de caer en manos de los inquisidores o en cuanto salen de la cárcel después de un proceso. Barrionuevo recordaba desde Madrid en el año de 1654 que «cada día quiebran y se van huyendo de la Inquisición, y después del auto de Cuenca me aseguran se han ido de Madrid mas de 200 casas con toda su familia a la deshilada, de la noche a la mañana. Todo esto puede el miedo» ${ }^{30}$. En Galicia, Jaime Contreras ha comprobado cómo de la noche a la mañana desaparecían una o varias familias porque, escribe:

«la verdad es que los esquemas clandestinos funcionan con más rapidez que las propias estructuras del tribunal: órdenes, contraórdenes, cartas a Madrid..., en resumen, poca eficacia» 31 .

Desde las altas esferas del poder inquisitorial se trata de reaccionar buscando nuevas estrategias de contención ante aquella marea emigratoria. La Suprema busca la colaboración ciudadana de seglares dispuestos a denunciar cualquier movimiento supuestamente sospechoso, pero también de los sacerdotes de las parroquias, conscientes del terror y cautelas que despiertan sus propios agentes. En una circular remitida a los tribunales les alertaba sobre la llegada a Madrid de muchos conversos procedentes de la mitad sur de la Península que pretendían proseguir viaje al Norte y cruzar la frontera:

30 Carta de 22 de agosto de 1654. Barrionuevo, Jerónimo de, Avisos... I, 1968, p. 48. Los contrabandistas encargados de ayudar a pasar la frontera con el menor peligro hacían su negocio en estos días. Algunos eran bien conocidos. De Gerónimo López se decía que su ocupación era «ir y venir a Francia», alquilando a litereros y organizando viajes. Francisco Fernández era conocido en Madrid y en todo el camino a Francia como «acarreador de judíos». Son sólo dos de los muchos casos que pueden rastrearse en la documentación. A.H.N. Inq. leg. 170/1. Proceso .5, fol.5-7.

31 Contreras Contreras, J.: El Santo Oficio de la Inquisición de Galicia. Madrid, 1982, p. 599. 
«posan en la calle angosta de San Bernardo, y suelen alquilar casas pequeñas y de una sóla vezindad en la calle de San Antón y barrios del hospital de San Andrés de los franceses, que son de la parroquia de San Luis, y tienen sus concurrencias en la Puerta del Sol y estanco General del Tabaco».

Y para mejor detectarlos, y poder detenerlos, sugerían una serie de actuaciones concretas como:

- pedir al teniente cura de San Luis la matrícula parroquial y comprobar en ella si están los nombres de aquellos sobre los que hay orden de prisión y, en este caso, sacar los datos de sus nombres y todos los que viven en la misma casa.

- investigar las señas y oficios de los anteriormente nombrados, pidiendo al teniente cura de San Luis sea él quién realice la investigación con cautela, ya que si ven a un ministro del Santo Oficio enseguida se ausentan.

- realizar esto mismo en las restantes parroquias de Madrid.

- tomar nota de todos los portugueses que aparezcan en los libros de matrícula aunque no estén en las listas para prenderse y dar relación de ello al Inquisidor de Corte.

- revisar los libros de huéspedes de las posadas, ya que «reconociéndolos con recato se suelen lograr prisiones».

- revisar quienes administran la renta del tabaco en todo el reino, "porque en éstos los más son de la nación y con este pretexto abrigan a muchos»

- reconocer las listas del correo que viene de Andalucía y Extremadura, contrastando los nombres con las listas de procesados por la Inquisición, «observando los nombres de los infectos y quién saca sus cartas y los que concurren a la Puerta del Sol» ${ }^{32}$.

Ante la presión, muchos van cayendo poco a poco. Hombres sencillos, tratantes y pequeños comerciantes, pero también grandes hacendados, se van dando cita en las prisiones inquisitoriales. La Inquisición no perdonó ni a los hombres de Estado. Manuel Cortizos y su familia es uno de los pocos conversos notorios que lograron librarse en aquel momento. Los escritos y crónicas de la época se hacen eco de las continuas detenciones que, pese al sigilo con que actuaban inquisidores y alguaciles, ya no pasaban desapercibidas para nadie en aquel Madrid de unos 130.000 habitantes :

«A media noche prendió la Inquisición catorce portugueses tratantes, hombres de negocios, en particular dos tabaquistas, uno de la Puerta del Sol y otro de Palacio. Esta gente retoña como hongos»

32 El documento que lleva el título de «Instrucción para la prisión de los reos fugitivos de las inquisiciones que vienen a esta Corte», carece de fecha y destinatario, aunque se encuentra entre documentación de mediados del siglo XVII, periodo al que parece pertenecer. Se encuentra en A.H.N. Inq. Leg. $4223, \mathrm{n}^{\circ} 2$. 
«Miercoles catorce de éste, a la una del día, prendió la Inquisición cuatro portugueses que tenían tienda de tabaco en Sto. Domingo, Red de San Luis, calle de Toledo y Plaza Mayor, portugueses todos y todos judíos» 33 .

Las cárceles se llenan y, desde Madrid, remiten a muchos a Cuenca porque la cárcel de Toledo no puede ya acoger a todos.

En estas circunstancias muchos no ven otra salida que intentar refugiarse al otro lado de los Pirineos donde, en torno a 1550, Enrique II de Francia había concedido permiso de residencia a los portugueses para que pudieran instalarse «en todas partes de este reino, como lo deseen, para dedicarse al comercio, adquirir propiedades y beneficiarse de los derechos y privilegios de que gozan los franceses ${ }^{34}$. Pero, pese a no existir prohibición legal de cruzar la frontera francesa, como contundentemente argumentaba ante los inquisidores conquenses el abogado defensor de Isabel Núñez en el proceso celebrado contra la suegra de Simón Fernández Miranda en 1655: «pues no es delito el irse qualquiera que es libre a Francia, antes es lícito y permitido el irse a la tierra que le pareciere y es muy conforme al derecho natural», los que se sabían testificados y buscados por la Inquisición no estaban dispuestos a esperar hasta ser hallados por algún comisario, lo que en la práctica solía suponer ir a la cárcel bajo la acusación de huir de la acción de la justicia ${ }^{35}$. Pero nos es bien conocido que, pese a las cautelas, las dificultades y los riesgos, el flujo de judeoconversos hacia Francia y otros paises europeos fue continuo en este periodo.

\section{EL VIAJE HACIA EL EXILIO DE LA FAMILIA FERNÁNDEZ MIRANDA}

La partida de Francisco Fernández Miranda fue precipitada. No se paró a vender o liquidar sus bienes, tal debió ser su percepción de peligro. Así que, una vez ausente de Andalucía y Madrid y cerca de la frontera francesa, debió esperar durante algo más de un año a que se vendiesen parte de sus bienes en

33 Barrionuevo, Jerónimo de, Avisos... A. Paz y Meliá (Ed.). Carta de 15 de septiembre de 1655, vol. I, p. 190 y de 21 de marzo de 1657 vol. II, p. 70. Madrid, 1968. Véase DomínGuEZ ORTIZ, A.: 1960 , p. 136.

34 BeInART, H.: 1993, p. 52. Sobre el incremento de emigrantes en este periodo, A. Domínguez Ortiz nos ha dejado escrito que es fruto de la conjunción de factores económicos, decadencia de Castilla en contraste con la prosperidad de los países del N. en los años 40-50 y político-religiosos que cristalizan en un aumento significativo de la represión. DOMINGUEZ ORTIZ, A.: 1960, p. 135.

35 A.H.N. Inq. Leg.170/1. Proceso V, fol. 69. La misma Isabel Núñez fue detenida en Negredo bajo esta acusación en 1655. Samuel Morteira se refería a esta búsqueda inquisitorial cuando en su Providencia de Dios con Israel... escribía: «Examínese también los grandes rigores que ay en los reinos de España y Portugal sobre no consentir salga ninguna nación judaica de dichos reinos, las grandes penas contra los transgresores, las visitas en los navíos, las guardas por los caminos y en suma el gran rigor que en esto usa la cruel Ynquisicion...», citado por MECHOULAN, H.: Hispanidad y judaísmo en tiempo de Espinoza. Salamanca, 1987, p. 34. 
Antequera y a que su mujer e hijos se reunieran con él ${ }^{36}$. Es a este periodo al que corresponden las cartas a las que nos hemos referido.

Desde su nueva residencia, Francisco se inquieta por la lentitud con la que se venden sus pertenencias y el descalabro de sus intereses económicos. En carta de 28 de septiembre de 1655 se lamentaba de las noticias que recibía sobre la venta de los objetos de plata de su propiedad por 6.000 reales, cuando su valor superaba los 20.000 , y de otras noticias que hablaban de que su esposa estaba malvendiendo precipitadamente sus propiedades en Antequera. Suplicaba, entonces, a su hermano Simón que acelerase el viaje de su familia a fin de frenar aquella dilapidación de sus bienes: «y assi le suplico quanto encaresidamente puedo disponga vuestra merced que se venga luego, aunque no sea sino con uno de sus hijos para su compañía» ${ }^{37}$. A mediados del mes de noviembre de ese mismo año, Clara y sus hijos viajaron efectivamente a Madrid para continuar viaje hasta Pamplona en cuanto les fuese posible. El lugar de referencia y residencia en la capital sería, como era habitual para la familia, la casa de Simón Fernández Miranda y Teodora Paula. Con fecha 17 de noviembre, Manuel escribía:

«el lunes pasado, quinze deste mes, salió desde aquí la gente en un coche. Va con ella mi sobrino... no ay sino, en llegando, despacharlo presto porque acá no tengamos algún ruido. Yo no pude juntar más de mill reales... que lleva para que en cuenta del viaje desde ay a Valladolid...».

En estos meses la preocupación de Francisco era ya su supervivencia en Francia. Naturalmente era difícil encontrar trabajo en Bayona o Peñaorada en un momento de tanto flujo migratorio: «los tiempos están de manera y corren tan adverssos, escribía Francisco, que bien es necessario el favor divino para podernos conservar...». La empresa exigía un gran esfuerzo personal y familiar. Consciente de las dificultades Francisco pide a Simón que recurra a otros miembros de la familia y a personas próximas. Concretamente le pide que hable con la prima

36 Esta sería la situación ateniéndonos al encabezamiento de las cartas que siempre se dataron en Pamplona, Vitoria o Burgos y teniendo en cuenta que pide dinero para proseguir el viaje. Sabemos que los datos personales que reflejan las cartas están adulterados para dificultar el rastreo a los inquisidores en caso de ser interceptadas, por lo que no podemos precisar el momento en que Francisco cruzó la frontera. Es posible que desde el principio estuviese en Bayona y que el intermediario que recogía las cartas en el Correo Mayor de Pamplona para él se las entregase en la ciudad francesa. Una carta de Clara Delgado a Simón durante el viaje para reunirse con su marido indica haber llegado a Pamplona el 30 de diciembre de 1655 y, según las noticias de Francisco, se encontraron el 5 de enero del 1656, lo que induciría a pensar que el reencuentro familiar no se produjo en Pamplona sino, muy probablemente, en Bayona.

37 Manuel Fernández Miranda, el tercer hermano todavía residente en Antequera donde tenía el cargo de escribano mayor del cabildo, confirma en carta a Simón que Clara ya ha vendido el mobiliario, que valora en 8.500 reales, el aguardiente que dejó fabricado Francisco y una mula, valorados asimismo en 4000 reales y casi todo su vestuario que valdrá otros 4000. A.H.N. Inq. Leg. 4275/2.

Hispania, LXIV/2, núm. 217 (2004) 543-570 
de Cisneros para que le preste dinero o le dé limosna para el viaje que le resta y el futuro inmediato ya que se ve muy necesitado y con muchos gastos "pues demás de hazerme tan gran beneficio y mersed es obra tan meritoria para con Dios...". Asimismo le pide que recuerde a "el ahijado", su hijo mayor Pedro en esta ocasión, le envíe periódicamente, cada 4 meses según precisa, el dinero que les permita ir viviendo "porque si no es desta manera, no podremos passar ni conservarnos y será peresser, porque aquí no ay quien nos socorra con un tan solo maravedí» ${ }^{38}$. Y es que, en estos períodos de tan fuerte intensificación del flujo emigratorio, la atención a los desposeídos, a tantos como llegaban sin medios de subsistencia, se hacía realmente difícil. La situación vivida en la Comunidad de Amsterdam ha sido dibujada por Yosef Kaplan cuando escribía:

«junto a los Suasso, los Pereyra, los Pinto, los Teixeira, los Curiel, y otras familias de magnates sefardíes, que asumieron el liderazgo comunitario de la "Nación", salieron de la Península Ibérica decenas de familias desprovistas de todo medio de subsistencia. Esta masa de inmigrantes pobres dio lugar a la formación de una densa población marginada socialmente, que vivía en dependencia total de las cajas de la sedeká (beneficiencia) de las comunidades sefardíes. Estos "pobres de la Nación" trabajaban, en el mejor de los casos, en las fábricas y refinerías de tabaco y azúcar establecidas por las grandes firmas sefardíes, o formaban parte de la servidumbre de las familias pudientes» 39 .

Simón Fernández Miranda, que después de un año de inactividad por su permanencia en la prisión se encontraba con importantes problemas financiéros, urgía a su hermano Manuel para que diera muestras de una mayor solidaridad y apoyo económico al hermano en problemas, pero tampoco Manuel pasaba por un buen momento económico. Responde a la demanda escribiendo:

" mas yo señor no puedo de una vez sacar partida grande, porque no tengo de dónde sino vendo una posesión, que toda mi riqueza está en ella como es notorio, y tengo muchos empeños y gastos. De lo que gano en los oficios, si voy reservando algo, que todo es poco, con ello acudo a hazer buenas obras, que yo también conosco a Dios, y siempre las he aplicado a mi hermano Francisco de Miranda» con el que, asegura, ya ha gastado mucho dinero y termina la carta asegurando a Simón que «no dexo de hazer la cossa porque no quiero, sino porque no puedo» ${ }^{40}$.

38 Carta de 13 de octubre de 1655, fechada en Vitoria. Su hermano Manuel confirma a Simón haber recibido para ayuda de Francisco 200 reales del Capitán Antonio de Soto que tenía información por el Doctor Sosa de los apuros económicos de Francisco. El añade otros 200 reales y envía una letra para que Simón la cobre y envíe la ayuda al hermano ausente.

39 KaPLAN, Y.: Judíos nuevos en Amsterdam. Barcelona, 1996, p. 117.

40 Todas las citas están tomadas de las cartas conservadas en el Leg.4275/2, ya citado. En este caso la carta tiene fecha de 20 de noviembre de 1655. Manuel termina reconociendo que es Simón el que asume como suyos todos los conflictos familiares «me pesa mucho que V.M. no esté muy sobrado, mas 
Mientras espera a la familia Francisco escribe frecuentemente a Simón. En ocasiones dirige las cartas para su hermano a Alonso de Ballado, lo hace bajo nombre falso y cambiando de nombre varias veces según evidencia la documentación y los hermanos se refieren a él siempre bajo el apelativo de «el compadre». En las cartas usa expresiones previamente acordadas y otras de carácter comercial con un significado diferente al habitual. Son estrategias reiteradas por los que se sienten amenazados e intentan ocultarse de los agentes inquisitoriales. Así, cuando se refiere a la espera de su mujer, habla de la parienta. A sus hijos adultos los nombra como ahijados y cuando quiere notificar la llegada de su mujer y su hijo dice haber recibido dos cargas de mercancías. El 4 de enero de 1656 escribía a Simón: «todavía no an llegado las cargas, si bien se a tenido noticia llegaron veinte leguas de aquí y que salieron el domingo próximo passado, con que se aguardan para mañana miércoles». Cuatro días después acusa recibo de las dos cargas de mercancías, en referencia a su mujer e hijo: «el miércoles en la noche 5 del corriente fue Dios servido que llegaron y entraron en esta ciudad las dos cargas de mercadurias que aguardaba...», reiterando días más tarde:

«como avisé a Vuestra Merced en el passado fue Dios servido que llegaron con bien las cargas, el miércoles passado en la noche, 5 del corriente, y fueron muy bien rresibidos del mercader y de todos los amigos ynteresados en ellas. Estimo mucho el cuidado de aberlas remitido y el favor que Vmd. nos haze...».

Y es que Clara y sus hijos habían estado en casa de Simón en Madrid entre noviembre y diciembre de 1655 mientras Simón organizaba y esperaba las circunstancias adecuadas para realizar, con las mejores garantías de seguridad, el viaje. Era muy consciente de las dificultades del proceso y de la necesidad de cuidar todos los detalles para culminar el proyecto con éxito. Tan sólo unos meses antes habían fracasado sus intentos por llevar a su suegra, Isabel Núñez, con su hermana María que ya residía en el Sur de Francia. Había concertado entonces el viaje con Jerónimo Gómez, que tenía larga experiencia en el trayecto, por 1.100 reales que había entregado de inmediato, pero la fatalidad había hecho volcar la litera que la trasladaba y que Isabel se lesionara en un brazo. Isabel interrumpió el viaje y se quedó en Negredo, a 20 leguas de Madrid, reponiéndose y a la espera de que la recogiera una nueva litera. Allí, tras las denuncias de un literero que conoció las circunstancias del viaje, fue detenida por Jacinto López de Cortés, familiar del Santo Oficio, y trasladada a Madrid y más tarde a Cuenca, en cuya prisión ingresó acusada de querer huir a Francia donde, en expresión del fiscal Dr. D. Diego de Escolano, «van los más portugueses observantes de la lei de Moisés para poder judaiçar con libertad» ${ }^{41}$. El fracaso

no me espanto con tantas tormentas, que ya veo yo que todo carga sobre V.M. y que a todo acude con
la voluntad de padre... nuestro Señor abrirá camino para que merescamos su gracia...».
41 A.H.N. Inq. Leg. 170/1. Proceso V, fol. 43 . Isabel Núñez había dejado la prisión de Cuenca
el 30 de junio de 1654 . En agosto, y después de haber pagado los 500 reales de multa impuestos en

Hispania, LXIV/2, núm. 217 (2004) 543-570 
del viaje fue para ella el final de aquel posible sueño de libertad. Isabel no volvió a intentar salir de Castilla y acabó sus días en la cárcel de la penitencia de la Inquisición toledana. El incierto y doloroso momento que vivía la familia Miranda, con Isabel en la prisión, obligaba a Simón a extremar las precauciones en la preparación del viaje de su cuñada y sobrinos.

Ante la percepción de los muchos riesgos del nuevo viaje y las suspicacias que despertaba el movimiento de grupos familiares, decidieron que la niña pequeña se quedase en casa de Simón y Teodora hasta encontrar una ocasión de poderla mandar con sus padres sin levantar sospechas. Los tiempos eran malos, la vigilancia mucha y el viaje, incluso si salía bien, era penoso. Camino de Pamplona, Clara Delgado escribía estar «mui cansada por ser los fríos y aguas muchas i estar el camino muy malo». Pero finalmente para ellos culminó con éxito. Antes de llegar al destino ya mostraba su preocupación por la hija que ha dejado en Madrid con sus cuñados, a los que escribe:

«les suplico hagan la limosna, de las muchas que acen, en cuidar de ese pedaço de mi coraçón como lo espero de su mucha caridad... asta que quiera Dios que allemos persona de confiança que me la encamine...». Y en otra carta: «estimaremos en el alma las buenas nuevas de la niña que le supplico se tenga el cuidado con ella que se espera de la merced que me haze en el ynter que se restituye a sus padres porque sin su compañía no podrían vivir» ${ }^{42}$.

Además del cambio de nombres era necesario tomar medidas cautelosas sobre la dirección a la que se dirigían las cartas y desde la que se remitía la correspondencia para evitar una localización fácil en caso de que las cartas cayeran en manos de funcionarios de la Inquisición o fuese denunciada la fuga. Lo habitual, que también constatamos en este caso, es que se enviasen las cartas en doble sobre. El visible se dirigía al correo Mayor de Pamplona para ser entregado a una persona con la que se establecía contacto y dispuesta a colaborar. En el interior otro sobre para el verdadero destinatario, aunque con nombre

\footnotetext{
la sentencia, pedía al Consejo de la Inquisición permiso para interrumpir el destierro que la obligaba a residir a 6 leguas de Madrid y Cuenca durante 2 años para pagar deudas contraídas en Madrid. El Consejo aceptó permitiéndole regresar a la capital. Cuatro procesos debieron parecer demasiados a la familia que proyectó una salida silenciosa del reino hacia Francia. Simón se encargó de proyectar el viaje, pero el intento fracasó en esa ocasión e Isabel volvió a ingresar en prisión el 28 de agosto de 1655, tan sólo un año después de haberla dejado. En la documentación inquisitorial pueden encontrarse referencias de otros viajes frustados por detención de los protagonistas. Por ejemplo en A.H.N. Inq. Leg. 139/19 o A.H.N. Inq. Lib. 1114.

42 Es éste el único dato que llama la atención de los inquisidores cuando revisan en los años 60 la voluminosa correspondencia de Simón y anotan: deja un niño en su casa. El resto lo consideraron sin interés. En esta ocasión no fueron capaces de ver que estaban ante los datos de una de tantas huidas a territorio francés. El análisis contrastado de estas cartas con las informaciones que salpican el quinto proceso de Isabel Núñez y el de su biznieta Juana Teodora no dejan, a nuestro entender, lugar a duda sobre la identidad de las personas y el significado de los mensajes.
}

Hispania, LXIV/2, núm. 217 (2004) 543-570 
supuesto, en este caso Francisco Antonio de Velasco. En carta de 4 de enero de 1656 Francisco establecía un cambio sobre lo que había sido habitual hasta ese momento, ya que había recibido varias cartas abiertas. Indica que las cartas debían dirigirse al Correo Mayor de Pamplona para ser entregadas a Diego Moreno que se las haría llegar a él:

«V. Md. se servirá de, en respuesta désta y de las demás que me hiziere merced de escribirme, que no vengan por la vía que an venido hasta ahora, sino de poner del sobreescripto de mi carta que diga a Francisco Antonio de Velasco, guarde Dios, en Pamplona, y hacer cubierta de ella en que diga: al Correo Mayor de Pamplona para que la dé a Diego Moreno, guarde Dios, en Pamplona, que es un amigo que me hace merced y me a afresido de recoxerlas» 43 .

En torno a esta creciente ola de viajes clandestinos surgieron naturalmente personas atentas a la ocasión de negocio que podían suponer tantos movimientos. Personas que se comprometían a acompañar a los que necesitaban cruzar la frontera con sigilo y que ofrecían conocimientos y contactos capaces de facilitar el éxito del viaje. Es el caso de Jerónimo Gómez, mercader gienense, al que Simón había contratado el viaje de su suegra hasta Bayona, y que al ser detenido confesó haber realizado 30 viajes en 6 años acompañando ocasionalmente a diferentes personas, o el de Miguel Méndez, residente en Bayona, que traía periódicamente mercancías desde la ciudad francesa a Madrid y regresaba con otros productos y con fugitivos, o el de Francisco Fernández al que se le apodaba como «acarreador de judíos» por su dedicación a facilitar la salida de judeoconversos y la fama que se había ganado de realizar con éxito sus viajes. Asimismo Rafael Gómez de Herrera confesó al ser detenido haber realizado uno o dos viajes al año desde Peñaorada con mercancías y algunos fugitivos, el literero Pedro Conde confesó ante los inquisidores haber llevado a Francia a diferentes personas en varios viajes, mientras Francisco Fernández Ríos acompañaba a extremeños que querían pasar a Peñaorada donde residían ya sus padres $^{44}$. El tribunal sevillano apodaba a Domingo Muñoz como «trajinador de judíos» y en sus reiterados viajes a Madrid recaudaba fondos para la sinagoga de Livorno ${ }^{45}$. En Madrid, por los años 50 del siglo XVII, los litereros Miguel de Çayas y Gerónimo Lorenzo fueron acusados igualmente de trasladar oculta-

43 Sobre el intercambio clandestino de cartas entre familiares residentes dentro y fuera de la Península, la duplicación de los sobres con la dirección y las estrategias de camuflaje seguidas para dificultar la tarea de identificación a los funcionarios inquisitoriales ha escrito Pilar Huerga. HUERGA CRIADO, P.: En la Raya de Portugal. Salamanca, 1993, pp. 253-257.

44 A.H.N. Inq. Leg. 170/1. Proceso V, fols. 2-10 y HUERGA CRIADO, P.: 1993, pp. 251-252. Rafael Gómez de Herrera es el que llevó a Clara Gómez y su hijo y anteriormente había participado en el intento de viaje de Isabel Núñez a Francia.

4s Domínguez OrTiz, A.: 1996, p. 244.

Hispania, LXIV/2, núm. 217 (2004) 543-570 
mente conversos a Francia, por sí mismos o por medio de sus criados Pedro Matalón y Domingo de la Fuente ${ }^{46}$.

La documentación nos permite creer que junto a personas que buscaban favorecer a los que se encontraban en peligro, por afinidad ideológica o de creencias, y que asumían el riesgo de unos viajes clandestinos que podían llevarlos a prisión en caso de ser descubiertos por agentes de la Inquisición, surgieron múltiples oportunistas que se aprovechaban de las situaciones de riesgo y necesidad para exigir pagos desorbitados, que duplicaban los cobros exigiendo dinero a los familiares de ambos lados de la frontera, que se quedaban con el dinero entregado por las familias para su entrega al final del viaje o que denunciaban a sus clientes cuando les convenía. Las situaciones fueron variadas y, en muchos casos, pintorescas. Cuando Clara y su hijo llegaron a Bayona, Francisco pidió al arriero la entrega del dinero que le habían dado para él en Madrid, una vez descontado el coste del viaje, ya que Simón le había informado de haberle dado 5000 reales. El transportista le aseguró que no sobraba nada y aún ser escasos los 1000 reales que había recibido, coste habitual de este tipo de viajes, ya que el viaje se había alargado 9 días sobre los 13 previstos inicialmente con el consiguiente aumento de los gastos. A Francisco no le quedó otra alternativa que asumir la situación. Era la consecuencia de una situación de ilegalidad en la que la clandestinidad y el secreto eran imprescindibles y no se podía reaccionar ante los posibles abusos:

«trata(n)do con el arriero me pagasse y restituyese el rrateo que llevó de más de los portes, me dixo que sólo se le dieron mil rreales de las dos cargas que traxo y que antes se le debían entregar más cantidad porque en el camino se detuvo 22 días donde tuvo muchos gastos».

Y de nada le sirvió a Francisco enseñarle la carta donde Simón aseguraba haberle entregado 5000 reales.

Pero una vez logrado el costoso objetivo de llegar a suelo francés, la evidencia de las dificultades dejaron empequeñecidas todas las previsiones y Francisco tuvo que insistir en pedir ayuda a la familia ${ }^{47}$. Pronto las dificultades y la experiencia cotidiana hicieron insostenible la situación del matrimonio en Peñaorada, así que, transcurridos sólo algunos meses Francisco decidió dejar a su mujer e hijo en Bayona y regresar a Andalucía donde, al amparo de la solidaridad familiar y grupal, encontraría rápidamente trabajo. Manteniendo el nombre de Francisco Antonio de Velasco se dirigió a la sierra de Alcaraz en Albacete donde nadie le conocía para trabajar allí como administrador de rentas, actividad

46 A.H.N. Inq. Lib. 1117

47 Ya el 26 de enero de 1656 recordaba a Simón lo mucho que necesitaba los 600 reales que estaba esperando le remitiese. Y. Kaplan ha destacado la presencia de una masa de pobres en la Comunidad judía de Amsterdam que, en ocasiones, se convirtieron en una pesada carga para la Comunidad. KAPLAN, Y.: 1996, pp. 116-117. 
que conocía bien ${ }^{48}$. En el año 1659 Francisco seguía en Alcaraz y con él estaba su hijo Antonio. Como Francisco Antonio de Velasco escribe desde la sierra albaceteña a su hijo Pedro de Ayala:

«yo quedo con salud y don Antonio para servir a Vuestra Merced en quanto nos mandare» y comenta el viaje que Antonio prepara a Madrid: «el viaje de don Antonio se a suspendido hasta de oy en ocho días... aunque me hará falta don Antonio por la soledad en que me allo, lo e tenido por bien su viaje por darle gusto y que cumpla con los deseos que tiene de ver a V. Md. y a mi señora doña Isabel» ${ }^{49}$.

Sin el apoyo de Simón, que ya ha fallecido en octubre del año 1656, es su hijo Pedro el que puede ayudar a la familia en espera de mejores tiempos. Al inicio de la siguiente década Francisco se trasladaría a Córdoba para trabajar en la tesorería de millones que administraba entonces su hijo mayor, Pedro de Miranda.

En esta época, y cuando lleva un largo periodo en España sin ser detectado por la Inquisición, inició los preparativos para que su mujer e hijos regresasen de Francia. Es la de Francisco la experiencia de muchos de los que partieron y que, tras lograr superar las dificultades para salir de España, tuvieron que regresar exponiéndose a ser identificados y denunciados porque el rapidísimo flujo de conversos hispanos hacia las ciudades del sur de Francia hacía imposible su integración laboral y profesional y conducía a muchos de ellos a la mendicidad y marginalidad social. Depender de las limosnas de familiares y amigos se convertía en algo extremadamente penoso y humillante y sólo algunos lograron salir con suficiente capital como para no temer el futuro o lograron encauzar su actividad profesional después de cruzar la frontera. En estas circunstancias, el regreso a España y sus riesgos se presentaba para Francisco, y para otros muchos, como un mal menor.

Según sabemos Simón Núñez regresó a España después de pasar varios años en Bayona al recibir una oferta de trabajo estable en el estanco de la sal; Juan de Molina dejó Burdeos para colaborar con Francisco López en la administración del tabaco de Granada; Juan López Arias vino desde Peñaorada a Cáceres para trabajar en los negocios de su hermano. Algunos incluso se arriesgaron a venir después de haberse circuncidado para integrarse plenamente en

48 Se conserva en el mismo legajo de correspondencia una carta suya remitida desde Alcaraz pidiendo al hermano residente en Madrid que remita urgentemente dinero a su familia en Francia que no pueden subsistir sin esa ayuda periódica. Desde Bayona le informan de la penuria y las muchas necesidades que están pasando: "llégame todo esto al alma ohir estas cosas y no podellas remediar», e insiste una vez más a Simón para que les envíe periódicamente dinero con el que se puedan sustentar.

49 Puede referirse a su sobrina Isabel de Miranda, en este momento ya viuda de Francisco Méndez Silva y gestora de una gran fortuna, lo que le daba prerrogativas ante la familia y posibilidades de ayudar en situaciones difíciles o, probablemente, a su hija Isabel Ana de Miranda, fruto, como Antonio, del segundo matrimonio de Francisco, y que trabajaba en Madrid en casa del doctor Sosa. 
la comunidad judía a la que se fueron. Es el caso de Jorge Núñez de Mercado que acabó siendo procesado saliendo al Auto de Fe de Cuenca en $1670^{50}$.

En 1661, cuándo Clara y sus hijos estaban de regreso en Madrid camino de Córdoba para reunirse con Francisco, el marido y padre, un denunciante que firma como D. Sebastián Muñoz escribía desde Peñaorada a la Inquisición de Corte dando todos los datos precisos para que pudieran detenerlos junto a otros familiares. Es un ejemplo elocuente de la colaboración y complicidad que el tribunal encontró en amplios sectores de la sociedad del XVII y que, en buena medida, justifican su eficacia y duración temporal. Por alguna circunstancia feliz para los Miranda los inquisidores madrileños se perdieron entre los nombres supuestos y los cambios de domicilios y nadie fue a prisión en este momento ${ }^{51}$. La carta dice textualmente:

«Señor mio, ynporta al servicio de Dios y a la exaltación de la fe que V.M., como buen ministro presente, luego que ésta llegare a sus manos, ante el Sr. Inquisidor Mayor para que sepa que en esta Corte ay un judio çircunçidado llamado D. Juan de Vitoria, que vive con su muger que se llama Doña Isabel, en casa de Doña Teodora Paula, los quales fueron de Françia para cobrar çierta herencia de un portugués que vivía en Marchena, que pienso hera mayordomo del conde y la muger hera su hija, y la envió a buscar, que vivia en Peñaorada, y hiço ynformaçión como habia asistido en Valladolid. En fin, préndanlos, que yo (a)seguro que se hallará ser verdad lo que yo digo y son primos hermanos. Las señas del hombre son ser de mediana estatura, de buena espalda, poco cabello, ojos reventones, labios gruesos; y ella flaca y ojos reventones y labios gruesos que en esto se parece con él. Y así no ay que dudar que D. Pedro de Miranda y Ayala arrendador de millones de Córdoba los oculta donde digo por ynstruirse en la mesma ley que, como no a estado en esta tierra, aunque lo $\mathrm{es}^{52}$, no es tan docto sino mediante la enseñanza del dicho D. Juan de Vitoria. Más agora ymbió a buscar a esta tierra a la muger de su padre, que a seis o siete años que vive en ella, y su marido está

50 Huerga Criado, P.: 1993, pp. 253-258. Yosef Kaplan confirma que de un modo u otro, a lo largo del siglo XVII, muchos miembros de la Comunidad judía de Amsterdam regresaron a España y Portugal o pasaron a las posesiones españolas en los Países Bajos o el Nuevo Mundo. KAPLAN, Y.: "The travels of portuguese jews from Amsterdam to the "lands of idolatry" (1644-1724)" en KaPLAN, Y. (Ed.): Jews and Conversos. Jerusalem, 1985, p. 203.

s1 También para mí ha sido complicado descifrar el significado de esta carta y poder relacionarla con el sigiloso regreso de la familia de Francisco Miranda desde suelo francés a Castilla. Afortunadamente los nombres y circunstancias referidos acabaron coincidiendo con datos verificados a través de otras fuentes documentales. No hay duda de que Sebastián Muñoz conocía bien a la familia Miranda. La misiva se encuentra incluída en el proceso de Juana Teodora de Silva. La misma Juana Teodora, después de denunciar a toda su familia ante la Inquisición de seguir judaizando, asegura no entender la carta ni saber a quiénes se refiere. Efectivamente muchos de los nombres han sido cambiados intencionadamente para evitar la identificación de las personas aludidas. A.H.N. Inq. Leg. 184/14, fols. 15-16. En el margen de la carta se anota: «V.M. dirá a esos señores que no comuniquen ninguna de estas cosas con Francisco Navarro porque es pariente y los a de avisar».

52 En referencia a que es criptojudío y sigue la Ley hebrea. 
ejerçiendo en millones en dicha tesoreria sino le an mudado en este tiempo por tenerle oculto y se llamaba en Antequera, donde hera escribano, Francisco de Miranda y después, por desconocerse, se llamó en Alcaraz donde fue administrador, Francisco Antonio de Velasco y en este tiempo pienso se mudó el Velasco. Es un hombre por ançiano casi de sesenta años muy alto y espalduro, los ojos reventones, la boca grande, pocos dientes, y la muger, una muger pequeña, boca grande, cabello negro azabachado y lo mesmo las çejas, blanca y bien carnuda y pareçida, tiene en un brazo una fuente y otra en una pierna y en el otro una señal de aber tenido otra y en la nuez unos cabellos negros a modo de lunar. Su propio nombre es Doña Clara Delgado, nazió en Estepa y vivió casada con el dicho Miranda en Antequera donde tenían la fabrica de aguardiente. Podrá ser que se haya mudado el nombre en Doña María de los Angeles, Doña Mariana de la Estrella o Doña Clara de Borja. Tiene un hijo llamado D. Jorge Mateo, de asta nueve o diez años, que él dirá luego toda la verdad y podrá ser que ya no estén en Madrid, que los haya llevado el dicho D. Pedro de Miranda a Córdoba para donde estaba de camino a su negoçio para de alli ymbiarla a su marido, que como digo es su padre, que también tengo notiçias lo quieren mudar a la sierra de Segura porque estén más ocultos. Sin embargo se pueden hazer diligencias en casa de Doña Isabel de Miranda, adonde habían de yr a posar, que es hija de la dicha Doña Teodora Pau$\mathrm{la}^{53}$. Tiene dicho D. Pedro correspondencia con un gran judío deste Santispiritus que por allá se llama Luis de Paz y acá Salomón de Paz, que fue quien avisó (a) esta muger por orden del dicho D. Juan de Vitoria que son primos hermanos. De manera que, con toda seguridad, se pueden prender éstos, que ellos dirán la verdad y en particular dicho Vitoria que está zircunçidado. Y también otro hermano de D. Pedro llamado D. Antonio de Miranda, que también a estado con su padre en esta tierra y a usado y usa del mismo rrito, pero no está zircuncidado.

Vm. sea servido, como digo, de poner ésta en las manos de los señores del tribunal y si me quisiere hazer respuesta venga por la estafeta de San Sebastián, poniendo en el sobreescrito de la cubierta: al correo mayor, para que la dé a Diego Moreno54 y dentro en el sobreescrito de la carta a D. Sebastian Muñoz en Peñaorada.

Guarde Dios a V.M. como deseo. En Bayona a 25 de septiembre de 1661. D. Sebastián Muñoz».

La carta nos enfrenta a dos temas de indudable interés histórico. Si por una parte pone de manifiesto la colaboración espontánea que la inquisición encon-

53 Teodora Paula, viuda de Simón Fernández Miranda, vivía en 1661 con Pedro de Miranda, el hijo mayor de Francisco Fernández Miranda y con su nieta Luisa Pato en la Carrera de San Jerónimo al lado del Hospital de los Italianos y frente al convento de Pinto. Es la misma casa donde anteriormente había residido la familia de Diego Gómez de Salazar con la que está fuertemente vinculada por antiguos lazos de amistad. Los Salazar habían trasladado su residencia a la calle de Alcalá, frente al convento de las Calatravas.

54 Según esta información Diego Moreno canalizaba hacia sus verdaderos destinatarios la correspondencia recibida en Pamplona o San Sebastián para varias personas residentes en Bayona, Peñaorada... A él se dirigían tanto las cartas para Francisco de Miranda como las que se pudieran enviar a D. Sebastián Muñoz, denunciante de la familia de Francisco. 
tró entre un sector de la población que percibía la disidencia y, particularmente la herejía, como un agente disturbador capaz de cuartear el sistema políticosocial del Antiguo Régimen ante el que la ciudadanía debía reaccionar, por otra nos sitúa ante la frecuencia de los viajes desde la Península Ibérica a otros territorios europeos y desde ellos a suelo español y portugués, con el indudable intercambio de conocimientos, ideas y vivencias que ello hubo que suponer. $Y$ es sobre este segundo punto sobre el que quiero hacer una breve reflexión convencida de que este hecho hubo de tener una trascendencia decisiva en el mantenimiento del marranismo penínsular, algo menos aislado de lo que suele presuponerse, ya que, desde mi percepción del tema, no se trata de hechos excepcionales ni singulares sino de una corriente subterránea continua, lenta en los períodos de reacción e incremento del control fronterizo y más intensa cuando las circunstancias lo permitían, pero, en cualquier caso, continua y plural.

En muchas ocasiones son los negocios los que conducían a judeoconversos hispanos a cruzar la frontera para entrevistarse personalmente con sus agentes y colaboradores, frecuentemente miembros de su propia familia emigrados con anterioridad a Bayona, Burdeos, Amsterdam... , para firmar acuerdos, disponer planes comerciales, trasladar mercancías, etc. En el verano de 1664, Gaspar Torres de Payba declaraba en una audiencia de su proceso haber estado en Bayona en 1658 donde vivía habitualmente su tío Gaspar Rodríguez Payba, añadiendo que también su hermano Manuel, residente en Valladolid, había pasado 4 ó 6 meses en la ciudad francesa en el año $1656^{55}$. Un pariente suyo, Gonzalo Báez de Paiba, confesó asimismo, ante el tribunal que le juzgaba al final de los años 50, que en 1657 había ido a Bayona donde, a instancias de una hermana suya que vivía en el barrio del Santo Espíritu como judía, se hizo circuncidar. Tiempo después regresó a Madrid haciéndose cargo de la administración de millones de Medina del Campo, eso sí, con el nombre supuesto de Gonzalo Pacheco de Luna, ya que la Inquisición ya le conocía y había preso en 1651. En 1659 cayó nuevamente en manos de los inquisidores que le procesaron y sentenciaron en Valladolid ${ }^{56}$.

En otros casos eran los «judíos nuevos» ${ }^{57}$ residentes en las comunidades francesas, holandesas o italianas los que venían temporalmente a España para aclarar y pactar negocios con sus corresponsales en la Península o para estudiar

55 A.H.N. Inq. Lib. 1135, fol. 354. B. López Belinchón cita los casos de Miguel de Sosa que gestionaba rentas a través de residentes en España e iba y venía frecuentemente a Madrid ò el de Baltasar de Paz que formaba compañía comercial con un hermano que residía en el S.O. francés y otro en Amsterdam, intercambiando mercancías entre los tres lugares. LÓPEZ BELINCHÓN, B.: 2001, pp. 1023, 1028 y 1035.

56 A.H.N. Inq. Leg. 138, $\mathrm{n}^{\circ}$ 132. WILleMSE, D.: Un portugués entre los castellanos. El primer proceso inquisitorial contra Gonzalo Báez de Paiba, 1651-1657. París, 1974 y CARo BAROJA, J.: 1978, I, pp. 491-493 y II, p. 399.

57 Judeoconversos hispanos que habían emigrado a países donde el judaísmo era aceptado, o consentido de hecho, y habían vuelto allí abiertamente al judaísmo.

Hispania, LXIV/2, núm. 217 (2004) 543-570 
posibilidades de trabajo en España. De ellos hablaba Francisco de Paz ante la Inquisición madrileña cuando afirmaba:

«...vienen muchos cada día a España a negociar y me parece que si por las fronteras de Francia estuviera ministro más celoso del servicio de Dios y del Santo Oficio que de sus intereses tendría cada día ocasión de coger muchos»s8.

En los años 30 Manuel Fernández Pato, conocido en Amsterdam como Jacobo Israel Díaz, vino y permaneció en Madrid en casa de su hermano Luis Fernández Pato algo más de un mes con la pretensión de quedarse a trabajar en los prósperos negocios familiares, pero Luis, temeroso del peligro que suponía su presencia para ambos, trató de disuadirle. Según su testimonio al regresar:

«le había tenido oculto en su casa sin dexarle salir ni comunicar con naide y que si alguna vez salía era en coche y que su venida había sido ver si podía estar en Madrid y ayudar a su hermano con seguridad de la Inqquisición y que, como estaba circuncidado, no se había atrevido y que así se volvía a Amsterdam»59.

De aquellos que procedían de la Comunidad judía de Amsterdam tenemos un mejor conocimiento por los trabajos del profesor Yosef Kaplan que evidencian la preocupación de los responsables de la comunidad ante la cuantía y frecuencia de estos viajes ya que, según evidencian sus investigaciones:

«decenas de judíos españoles y portugueses, ex-conversos y descendientes de cristianos nuevos refugiados en las "tierras de judesmo", emprendían anualmente el trayecto que les conducía de las comunidades judías a las "tierras de idolatría ${ }^{6}{ }^{60}$.

Tal fue así que, desde la comunidad sefardí de Amsterdam, se creyó necesario establecer leyes que impidieran estos movimientos a las «tierras de idolatría» donde los judíos tenían que pasar por cristianos y ello les impedía el cumplimiento preciso de los preceptos judaicos. El profesor jerosolimitano ha identificado 85 casos de miembros de la Comunidad de Amsterdam que, a su

s8 A.H.N. Inq. Lib. 1114, cit. por Huerga Criado, P.: 1993, p. 252. De la misma autora, véase «Entre Castilla y los Paises Bajos. Lazos familiares y relaciones personales», en VV.AA., Familia, religión y negocio. Madrid, 2003, p. 50.

59 Recogido en el primer proceso de Luis Fernández Pato. A.D.C. Inq: Leg. 728/1225. Un testigo del mismo proceso, Francisco Serrano, asegura haber visto a Luis Fernández Pato en Amsterdam acompañando a su familia a la sinagoga donde «le vio rezar con los demás en un libro hebrayco» y "guardar los sábados sin negociar en ellos y poniéndose vestidos mejorados». A.D.C. Inq. Leg. $455 / 6292 \mathrm{G}$

60 KAPLAN, Y.: «La diáspora judeo-española-portuguesa en el siglo XVII: Tradición, cambio y modernización», en Manuscrits, 10,1992, p. 82. Se usa el término en referencia a España, Portugal y otros lugares en los que el judaísmo era considerado ilícito. Véase KAPLAN, Y.: 1996, p. 28.

Hispania, LXIV/2, núm. 217 (2004) 543-570 
regreso, pidieron públicamente perdón por haber violado estas prohibiciones viajando a España. Otros muchos de los que viajaban eludirían la petición de perdón y compromiso con la comunidad porque pensaban seguir viajando periódicamente ${ }^{61}$ y, en otros casos, al regreso de la Península se integrarían en otra comunidad diferente ${ }^{62}$. No era muy distinta la situación en las comunidades sefardíes más próximas a la frontera, donde el profesor Révah ha comprobado como "muchos marranos iban y volvían entre el sodoeste de Francia y España...» ${ }^{63}$

Además de estos viajes de ida y vuelta, sabemos que muchos judeoconversos, después de salir de España e integrarse en comunidades judías, decidieron regresar a la Península desafiando los peligros que ello comportaba. Los problemas económicos, muy frecuentemente, y las dificultades para integrarse en una comunidad judía formal, después de haber pasado una parte importante de la vida viviendo muy parcialmente y en secreto el judaísmo, forzaron el regreso de muchos.

Conocemos casos en los que al regreso se optó por colaborar abiertamente con la Inquisición buscando la plena integración en el cristianismo. Es el caso de Esteban Arias de Fonseca, judío circunciso, que en 1635 regresaba a España convirtiéndose en confidente de la Inquisición y denunciando a muchos de los que vivían en el extranjero como judíos y eran buscados por la Inquisición ${ }^{64}$.

En algunos casos los que viajaban fueron detectados por la Inquisición y se les incoaron procesos. En 1640, Jorge Núñez de Mercado estuvo y vivió como judío en Amsterdam y fué circuncidado. Pese al peligro añadido que ello suponía, iba y venía a España frecuentemente dando diversos nombres hasta que en 1670 fue detenido y conducido a la prisión de Cuenca. Simón Núñez vivió en el barrio del Spíritu Santo de Bayona hasta que una oferta de trabajo en España le animó a regresar a Extremadura. Es un caso similar al de Juan López Arias que regresó para trabajar con su hermano que había permanecido en Cáceres o el de Juan de Molina que, después de intentar integrarse en la comunidad de Burdeos, regresó para trabajar en la renta de tabaco en Granada ${ }^{65}$. En este tra-

61 Ese podría ser el caso de Francisco López de Capadocia que se negó a circuncidarse pese a las presiones de la Comunidad sefardí de Amsterdam. KAPLAN, Y.: 1996, p. 32. Al menos desde los años 50 reside y negocia en Madrid, donde, en 1651 casó, en la parroquia de San Martín, a su hija Juana López de Capadocia con Luis Fernández Pato, conocido hombre de negocios reiteradamente procesado por la Inquisición y cuya familia residía en Amsterdam, desde tiempo atrás, plenamente integrada en la Comunidad judía. Francisco sufrió dos procesos, en 1653-55 y en 1663-70, terminando sus días en la prisión inquisitorial toledana.

62 KAPLAN, Y.: 1992, p. 82.

63 RÉVAH, I. S.: «La herejía marrana en la Europa católica en los siglos XV al XVIII», en Herejias y sociedades en la Europa preindustrial (s. XI al XVIII) . Madrid, 1987, p. 251. De los movimientos entre las juderías norteafricanas y España ha escrito Mercedes García Arenal. Véase García Arenal, M. y Wiegers, G., 1999, pp. 33-35.

64 Véase KaPLAN, Y.: 1985, p. 204.

65 Huerga Criado, P.: 1993, pp. 253-256. 
bajo nos hemos ocupado del caso de Francisco Fernández Miranda y su familia directa. Sabemos de su regreso por la denuncia de Sebastián Muñoz y, pese a ella, los inquisidores no lograron pruebas para incoar un proceso que tuviera posibilidades de éxito.

Pero también cabe pensar que otros muchos lograron su objetivo de pasar desapercibidos para el aparato inquisitorial, permaneciendo bastante invisibles para los estudiosos al no dejar rastro en la documentación inquisitorial, aunque sus huellas podrían ser perceptibles en otro tipo de documentación.

Pese a la movilidad, la relación, lazos e intercambio entre unos y otros perduraron más allá de las distancias y desplazamientos. Sabemos bien que las diferentes ramas familiares dispersas por diversos países europeos mantuvieron una fluida relación económica y de negocios ${ }^{66}$, pero que también perduraron los vínculos sociales, de afecto y de ideas que la frecuente comunicación epistolar y los contactos periódicos ayudaron a mantener vivos. La relación humana entre los miembros dispersos de una misma familia fue permanente y se prolongó en el tiempo pese a las dificultades y por encima de las opciones religiosas y profesionales de cada uno ${ }^{67}$. Judíos integrados en la comunidad de Amsterdam, o cristianos que vivían abiertamente el judaísmo con el que se identificaban en territorio francés o italiano, mantuvieron una corriente de comunicación continua con sus familiares en la Península, ya estuvieran integrados realmente en la sociedad cristiana mayoritaria o vivieran externamente como cristianos manteniendo un fuerte vínculo interno con el judaísmo en espera de poder integrarse algún día en una comunidad judía. Normalmente los vínculos parentales se mantuvieron durante generaciones, pese a las distancias y las dificultades de comunicación, los conflictos y rupturas, los desencuentros y rivalidades. Y ello fue posible, en buena medida, por los contactos que, aunque difíciles y esporádicos, fueron, sin embargo, siempre buscados y en muchas ocasiones se materializaron e hicieron posibles, reavivando el afecto y los vínculos formales.

No son pocos los casos en que consta que el objetivo central de los viajes no fueron los negocios sino el deseo de estar con parte de la familia, vivir con ellos determinadas celebraciones litúrgicas o establecer contactos con vistas a un futuro matrimonio. Este último fue el caso de Domingo Gutiérrez, alias Luis

66 La importancia y características de esta relación y redes comerciales han sido estudiadas por BROENS, N.: 1989, ISRAEL, Y. I.: 1992 o LÓPEZ BELINCHÓN, B.: 2001, entre otros.

67 Lo ha destacado el profesor Yosef Kaplan al afirmar «la permanente vinculación de los conversos ya integrados al judaísmo con los judeoconversos de España y Portugal y sus respectivas colonias. Todo judío nuevo de Amsterdam, Hamburgo o Londres estaba íntimamente ligado a parientes allegados en Sevilla, Málaga, Lisboa u Oporto", insistiendo en que los vínculos de parentesco perduraron a través de generaciones y pese a las distancias. KAPLAN, Y.: 1996, pp. 109-110. Véase asimismo BODIAN, M: «La diáspora de los conversos sefardíes y los cambios en la apreciación del exilio judío", en VV.AA., Familia, religión y negocio. Madrid, 2003, p. 34. 
Antonio de Ribera, que en 1666 fue a Peñaorada para casarse, según la Ley de Moisés, con Isabel Luisa de la Torre ${ }^{68}$.

Pero, fuera cual fuese el objetivo de los múltiples viajes, los residentes hispanos que acudían temporalmente a las comunidades judías reavivaban y actualizaban sus vivencias y costumbres judaicas compartiéndolas al regreso con el núcleo familiar y de amistad más próximo. Igualmente la llegada de algún judío procedente de las comunidades holandesas, o de cristianos que vivían más o menos abiertamente el judaísmo en Francia, Flandes, Italia..., promovía reuniones y encuentros donde se comunicaban experiencias o se asumía la representación y dirección de celebraciones rituales. Todo ello, como no podía ser de otro modo, tuvo una enérgica influencia sobre la vitalidad y perduración temporal de costumbres y vivencias judaicas en la Península que, aunque sin proyección pública, debieron mantenerse vivas en la España de Felipe IV, en la intimidad de muchos hogares de los descendientes de los judeoconversos españoles.

68 A.H.N. Inq. Lib. 1137, fol. 69. 